\title{
Microarray analysis in B cells among siblings with/without MS - role for transcription factor TCF2
}

\author{
Jagannadha R Avasarala*1, Sridar V Chittur ${ }^{2}$, Ajish D George ${ }^{2}$ and \\ John A Tine ${ }^{2}$
}

Address: ${ }^{1}$ Multiple Sclerosis Specialty Care, Kansas Neurological Consultants, PA, Wichita, KS 67218, USA. and ${ }^{2}$ Center for Functional Genomics and Department of Biomedical Sciences, University at Albany, SUNY, Rensselaer, NY 12144, USA.

Email: Jagannadha R Avasarala* - javasarala@yahoo.com; Sridar V Chittur - schittur@albany.edu; Ajish D George - ajishg@gmail.com; John A Tine - jtine@csc.albany.edu

* Corresponding author

Published: 31 January 2008

BMC Medical Genomics 2008, 1:2
Received: 17 July 2007

Accepted: 31 January 2008

This article is available from: http://www.biomedcentral.com/l755-8794/I/2

(c) 2008 Chittur et al; licensee BioMed Central Ltd.

This is an Open Access article distributed under the terms of the Creative Commons Attribution License (http://creativecommons.org/licenses/by/2.0), which permits unrestricted use, distribution, and reproduction in any medium, provided the original work is properly cited.

\begin{abstract}
Background: We investigated if global gene expression and transcription networks in Blymphocytes of siblings with multiple sclerosis (MS) were different from healthy siblings.

Results: Using virus-transformed immortalized $B$ cells and human whole genome bioarrays with validation using RT-qPCR, we found that in siblings with MS, genes for CXCLI0, serpin $B I$ and FUT4 were up regulated whereas CDC5L, TNFRSFI 9 and HLA-DR were down regulated, among others; transcription analysis showed two intersecting clusters of transcriptional factors - the larger, governed by the upregulated transcription factor 2 (TCF2) and the smaller network regulated by the downregulated $\mathrm{CDC} 5 \mathrm{~L}$.
\end{abstract}

Conclusion: No study has linked TCF2 to MS and to better understand the role of TCF2 in MS, studies in larger cohorts are required.

\section{Background}

MS is a complex genetic disease associated with inflammation predominantly in the white matter of brain and spinal cord. It is thought to be mediated by autoreactive T cells $[1,2]$. Susceptibility to MS is determined by both inherited and non-inherited factors [3]. Approximately $15-20 \%$ of MS patients have a family history of MS, but large extended pedigrees are uncommon. Studies in twins $[4,5]$ and conjugal pairs [6] show that much of the familial clustering is the result of shared genetic risk factors.

MS susceptibility is linked to HLA-DR2 [7]. Increased risk of MS in women has been detected with interleukin-1 receptor antagonist (IL-1RA) allele 2 [8], 5G5G genotype of plasminogen activator inhibitor 1 (PAI-1) gene [9] and interaction between estrogen receptor 1 (ESR1) and HLADR2 [10]. B cells are implicated in MS and have been found in the cerebrospinal fluid (CSF) of MS patients [11]. Additionally, oligoclonal bands identified in CSF point to the role of B cells in MS pathogenesis [12]. Furthermore, antibody-secreting $\mathrm{B}$ cells contribute to tissue injury [13]. We hypothesized that B cells derived from MS patients could harbor genes that confer a higher MS risk as compared to B cell gene expression in healthy siblings.

Human B-cells have a receptor for Epstein-Barr virus (EBV) and can become immortalized after in vitro infection with EBV. Additionally, the link between EBV and MS 
is highly impressive [14] though inconclusive; we hypothesized that analysis of gene expression and transcription networks in EBV-transformed B cells between siblings with and without MS could yield important clues to understanding the pathology of MS.

Large-scale analyses of transcripts from peripheral blood cells or brain lesions from MS patients have created possibilities for therapeutics [15] and global gene expression analysis using microarrays is a sensitive method to investigate molecular heterogeneity [16]. In this study, we tested a new software tool that is in development, to map transcription networks in the microarray data.

Our objectives were to i) to determine if gene expression and transcription networks in B-lymphocytes of siblings with MS were different from healthy siblings in EBV-transformed B cells and ii) to validate data using qPCR techniques.

\section{Methods}

EBV-transformed B cell lines from Coriell Institute for medical research (Camden, NJ, USA) and the National Institute of General Medical Sciences (NIGMS, Bethesda, MD) were obtained for our study. As shown in Table 1, B cells were harvested from one family (\# 2108, proband, affected sister) and an unaffected brother (control); cells from another family (\# 2112, proband, affected brother) and three unaffected brothers (controls). Cells from the third family (\# 2102) comprised of proband and an affected sister but no unaffected controls. None of the patients were on immunomodulatory agents (IMAs) to treat MS.

Cells were harvested in $4 \mathrm{ml}$ of Tri-Reagent (Molecular research center, Inc) and the total RNA was isolated using standard protocols. Briefly, B-cells were incubated at $37^{\circ} \mathrm{C}$ and $5 \% \mathrm{CO}_{2}$ overnight, the day after cells were counted. Cells were expanded in RPMI 1640 with $2 \mathrm{mM} \mathrm{L-}$ glutamine and 15\% fetal bovine serum following Coriell's lymphoblast line maintenance protocols. 2 vials were fro- zen and $1 \times 10^{7}$ cells were spun down and resuspended in $2 \mathrm{ml}$ of Tri-reagent. The cell mixture was frozen at $-80^{\circ} \mathrm{C}$ until further analysis. The RNA was isolated using the standard Tri-reagent protocol and further cleaned up using RNeasy kits (Qiagen) using a protocol that included an on column Dnase step. RNA samples were checked for quality on a Bioanalyzer and a nanodrop spectrophotometer. Samples with $28 \mathrm{~s} / 18 \mathrm{~s}$ ratio $>1.8$ were deemed acceptable for the microarray experiment. The total RNA ( $1 \mathrm{ug}$ ) was first converted to double stranded cDNA using the standard Codelink protocol. This was then purified on Qiaquick PCR columns and in vitro transcribed to labeled cRNA using biotin-11-UTP (Perkin Elmer). The labeled cRNA was purified on Qiagen RNeasy Mini columns and $10 \mathrm{ug}$ was fragmented as per the Codelink protocol following which it was hybridized to the Codelink Human Whole Genome bioarrays for $18 \mathrm{~h}$ at $37^{\circ} \mathrm{C}$. The arrays were subsequently washed, stained with Cy5-Streptavidin (GE Amersham) and scanned on an Axon Genepix 4000B scanner. The data were collected using Codelink Expression Analysis software and analyzed using Genespring software version 7.3.1 (Agilent). All microarray data are deposited at Gene Expression Omnibus as GSE 10064 and linked via [17].

\section{Microarray data analysis}

Values below 0.01 were set to 0.01 . Each measurement was divided by the 50th percentile of all measurements in that sample. All samples were normalized to the median of the control samples. Each measurement for each gene in those specific samples was divided by the median of that gene's measurements in the corresponding control samples. The gene list (54,902 transcripts) was filtered using the cross gene error model for replicates to select genes with good signal-to-noise ratios (31, 168 genes). This gene list was subjected to a student's t-test (p-value < 0.05 ) and yielded 1, 417 genes with significant differences between the two conditions. This list was further filtered for confidence using a Benjamini-Hochberg false discovery rate correction to obtain 1405 genes. A 1.5-fold cut-off filter was then applied to identify genes that were prefer-

Table I: Cell lines obtained from Corielle for our study.

\begin{tabular}{|c|c|c|c|c|c|}
\hline Sample ID & Relation & Family & Affected & Sex & Age \\
\hline GM8923 & Proband & 2108 & Yes & Male & 38 \\
\hline GM8922A & Sister & 2108 & Yes & Female & 43 \\
\hline GM8830 & Proband & 2102 & Yes & Female & 47 \\
\hline GM8839 & Sister & 2102 & Yes & Female & 39 \\
\hline GM9013 & Proband & 2112 & Yes & Male & 35 \\
\hline GM90I6 & Brother & 2112 & Yes & Male & 38 \\
\hline GM9018 & Brother & 2112 & No & Male & 42 \\
\hline GM9017 & Brother & 2112 & No & Male & 45 \\
\hline GM9023 & Brother & 2112 & No & Male & 47 \\
\hline GM892 IA & Brother & 2108 & No & Male & 46 \\
\hline
\end{tabular}


entially upregulated (260) or downregulated (452) genes in samples with disease as compared to controls. These 712 genes were further filtered to only select those which were consistently 'absent" or "present" in 3 of 4 controls and 5 of 6 diseased samples. The final gene list had 705 genes; 259 upregulated and 446 downregulated genes while using 2-fold cut off resulted in 84 upregulated and 111 downregulated genes (Tables 2 \& 3).

\section{Hierarchical clustering}

This gene list was subjected to a hierarchical clustering routine in GeneSpring using a Pearson correlation similarity measure across conditions and a standard correlation similarity measure across genes. The final tree is represented in Figure 1.

Table 2: Representative upregulated genes (out of 259 total).

\begin{tabular}{|c|c|c|c|c|}
\hline Probe ID & Fold Change & Common & Genbank & Description \\
\hline \multicolumn{5}{|c|}{ Upregulated genes } \\
\hline GE53598 & 5.88 & TINAG & NM 014464 & tubulointerstitial nephritis antigen, complete cds \\
\hline GE59642 & 5.77 & CXCLIO & $\overline{N M 001565}$ & gamma-interferon inducible early response gene (with homology to platelet proteins) \\
\hline GE57550 & 4.74 & CRYM & NM 001888 & mu-crystallin mRNA, complete cds \\
\hline GE5 18123 & 4.27 & IGLLI & NM 020070 & immunoglobulin lambda-like polypeptide I (IGLLI), transcript variant I, mRNA \\
\hline GE58736 & 4.20 & DACTI & NM 016651 & dapper homolog I, antagonist of beta-catenin (xenopus) (DACTI), mRNA \\
\hline GE79033 & 4.15 & CD9 & NM 001769 & CD9 antigen (p24) (CD9), mRNA \\
\hline GE55346 & 3.57 & LRRCI6 & NM 017640 & leucine rich repeat containing $16(\mathrm{LRRCI} 6)$, mRNA \\
\hline GE6I 239 & 3.50 & SERPINBI & NM 030666 & $\begin{array}{l}\text { serine (or cysteine) proteinase inhibitor, clade B (ovalbumin), member I (SERPINBI), } \\
\text { mRNA }\end{array}$ \\
\hline GE6278I & 3.50 & MTIF & NM 005949 & metallothionein IF (functional) (MTIF), mRNA \\
\hline GE8750। & 3.49 & FXYD2 & NM 001680 & FXYD domain containing ion transport regulator 2 (FXYD2), transcript variant a, mRNA \\
\hline GE61946 & 3.26 & ARHGAP6 & NM 001174 & Rho GTPase activating protein 6 (ARHGAP6), transcript variant 2, mRNA \\
\hline GE56932 & 3.22 & EGLN3 & NM 022073 & egl nine homolog 3 (C. elegans) (EGLN3), mRNA \\
\hline GE61093 & 3.18 & ACTNI & NM 001102 & actinin, alpha I (ACTNI), mRNA \\
\hline GE87626 & 2.97 & OSR2 & NM 053001 & odd-skipped-related 2A protein (OSR2), mRNA \\
\hline GE59655 & 2.93 & ATPIBI & NM 001677 & ATPase, $\mathrm{Na}+/ \mathrm{K}+$ transporting, beta I polypeptide (ATPIBI), mRNA \\
\hline GE58575 & 2.91 & PTPLA & NM 014241 & $\begin{array}{l}\text { protein tyrosine phosphatase-like (proline instead of catalytic arginine), member a } \\
\text { (PTPLA), mRNA }\end{array}$ \\
\hline GE57767 & 2.84 & COL9A3 & NM 001853 & collagen, type IX, alpha 3 (COL9A3), mRNA \\
\hline GE57621 & 2.83 & LGALS3BP & NM 005567 & lectin, galactoside-binding, soluble, 3 binding protein (LGALS3BP), mRNA \\
\hline GE8I389 & 2.82 & CCR6 & NM 004367 & chemokine ( $\mathrm{C}-\mathrm{C}$ motif) receptor 6 (CCR6), transcript variant I, mRNA \\
\hline GE79898 & 2.81 & LYPLA3 & NM 012320 & lysophospholipase 3 (lysosomal phospholipase A2) (LYPLA3), mRNA \\
\hline GE62292 & 2.79 & CPXM & NM 019609 & carboxypeptidase X (MI4 family) (CPXM), mRNA \\
\hline GE57547 & 2.66 & TCN2 & NM 000355 & transcobalamin II; macrocytic anemia (TCN2), mRNA \\
\hline GE8I 525 & 2.52 & $\mathrm{IFI} 27$ & NM 005532 & ISG I 2 protein \\
\hline GE7964I & 2.48 & FUT4 & NM 002033 & fucosyltransferase 4 (alpha $(\mathrm{I}, 3)$ fucosyltransferase, myeloid-specific) (FUT4), mRNA \\
\hline GE8I 272 & 2.47 & VIM & NM 003380 & vimentin (VIM), mRNA \\
\hline GE57737 & 2.45 & ENPP2 & NM 006209 & autotaxin mRNA, complete cds \\
\hline GE80I50 & 2.38 & ELF3 & NM 004433 & E74-like factor 3 (ets domain transcription factor, epithelial-specific) (ELF3), mRNA \\
\hline GE58207 & 2.34 & ENG & NM 000118 & endoglin (Osler-Rendu-Weber syndrome I) (ENG), mRNA \\
\hline GE57048 & 2.33 & CCRI & NM 001295 & chemokine (C-C motif) receptor I (CCRI), mRNA \\
\hline GE57883 & 2.28 & SELL & NM 000655 & selectin L (lymphocyte adhesion molecule I) (SELL), mRNA \\
\hline GE602I 4 & 2.27 & NRGN & NM 006176 & neurogranin (protein kinase $C$ substrate, $R C 3)$ (NRGN), mRNA \\
\hline GE498904 & 2.22 & DACTI & NM 016651 & dapper homolog I, antagonist of beta-catenin (xenopus) (DACTI), mRNA \\
\hline GE8I340 & 2.17 & PSTPIPI & NM 003978 & proline-serine-threonine phosphatase interacting protein I (PSTPIPI), mRNA \\
\hline GE5893। & 2.16 & TCF8 & $\underline{\mathrm{U}} 2170$ & zinc finger homeodomain protein mRNA, complete cds \\
\hline GE6I464 & 2.15 & SERPINB9 & NM 004155 & $\begin{array}{l}\text { serine (or cysteine) proteinase inhibitor, clade B (ovalbumin), member } 9 \text { (SERPINB9), } \\
\text { mRNA }\end{array}$ \\
\hline GE82947 & 2.12 & SNX22 & NM 024798 & sorting nexin 22 (SNX22), mRNA \\
\hline GE60I34 & 2.09 & UPPI & $\overline{N M 003364}$ & uridine phosphorylase (UP), transcript variant I, mRNA \\
\hline GE54I52 & 2.07 & APOLI & $\overline{N M 003661}$ & apolipoprotein L, I (APOLI), transcript variant I, mRNA \\
\hline GE56786 & 2.02 & DUSP4 & NM 001394 & dual specificity phosphatase 4 (DUSP4), transcript variant I, mRNA \\
\hline GE54528 & 2.02 & TNFSFI 2 & NM 003809 & $\begin{array}{l}\text { tumor necrosis factor (ligand) superfamily, member I } 2 \text { (TNFSF I2), transcript variant I, } \\
\text { mRNA }\end{array}$ \\
\hline GE61789 & 2.02 & TDE2L & NM 178865 & tumor differentially expressed protein 2 (TDE2), mRNA \\
\hline GE61399 & 2.01 & LLTI & NM 013269 & lectin-like NK cell receptor (LLTI), mRNA \\
\hline
\end{tabular}

Fold change $=$ diseased $/$ normal 
Table 3: Representative downregulated genes (out of 446 total)

\begin{tabular}{|c|c|c|c|c|}
\hline Probe ID & Fold change & Common & Genbank & Description \\
\hline \multicolumn{5}{|c|}{ Down regulated genes } \\
\hline GE54030 & $0.09^{\circ}$ & EIFIAY & NM 004681 & eukaryotic translation initiation factor IA, Y-linked (EIFIAY), mRNA \\
\hline GE79500 & 0.1 & RPS4Y & $\overline{N M 001008}$ & ribosomal protein S4, Y-linked (RPS4Y), mRNA \\
\hline GE54029 & 0.12 & DDX3Y & NM 004660 & DEAD/H (Asp-Glu-Ala-Asp/His) box polypeptide, $Y$ chromosome (DBY), mRNA \\
\hline GE59227 & 0.12 & JARIDID & $\overline{N M 004653}$ & Smcy homolog, Y-linked (mouse) (SMCY), mRNA \\
\hline GE55836 & 0.15 & MLAT4 & NM 018192 & myxoid liposarcoma associated protein 4 (MLAT4), mRNA \\
\hline GE54974 & 0.19 & TNFRSFI9 & NM 148957 & $\begin{array}{l}\text { tumor necrosis factor receptor superfamily, member } 19 \text { (TNFRSFI9), transcript variant } 2 \text {, } \\
\text { mRNA }\end{array}$ \\
\hline GE7884I6 & 0.28 & KRTAP4-9 & A) 406941 & partial mRNA for keratin associated protein 49 (KRTAP4.9 gene) \\
\hline GE489986 & 0.32 & ZFY & NM 0034II & zinc finger protein, $Y$-linked (ZFY), mRNA \\
\hline GE58359 & 0.35 & GCHFR & NM 005258 & GTP cyclohydrolase I feedback regulatory protein (GCHFR), mRNA \\
\hline GE87376 & 0.36 & BAIAP2LI & $\overline{N M 018842}$ & insulin receptor tyrosine kinase substrate (LOC5597I), mRNA \\
\hline GE56I 268 & 0.39 & FOXD4L2 & NM 199135 & FOXD4-like 2 (FOXD4L2), mRNA \\
\hline GE54486 & 0.4 & DAPK2 & NM 014326 & death-associated protein kinase 2 (DAPK2), mRNA \\
\hline GE79999 & 0.4 & CAMKI & NM 003656 & calcium/calmodulin-dependent protein kinase I (CAMKI), mRNA \\
\hline GE58। 78 & 0.4 & KALI & $\overline{N M 000216}$ & Kallmann syndrome (KAL) mRNA, complete cds \\
\hline GE82446 & 0.4 & BAIAP2LI & NM_018842 & insulin receptor tyrosine kinase substrate (LOC5597I), mRNA \\
\hline GE58327 & 0.41 & CD83 & $\overline{N M 004233}$ & CD83 antigen (activated B lymphocytes, immunoglobulin superfamily) (CD83), mRNA \\
\hline GE567535 & 0.42 & NGFRAPI & $\mathrm{AFI} 87064$ & p75NTR-associated cell death executor (NADE) mRNA \\
\hline GE62339 & 0.42 & CSE-C & NM 018978 & sialic acid-specific 9-O-acetylesterase I mRNA, complete cds \\
\hline GE828I5 & 0.42 & $\mathrm{FA} 2 \mathrm{H}$ & $\overline{N M 024306}$ & fatty acid 2-hydroxylase (FA2H), mRNA \\
\hline GE82367 & 0.44 & LAPTM4B & NM 018407 & $\begin{array}{l}\text { lysosomal associated protein transmembrane } 4 \text { beta (LAPTM4B), mRNA phosphodiesterase } \\
\text { 4A, cAMP-specific (phosphodiesterase E2 dunce homolog, Drosophila) }\end{array}$ \\
\hline GE81609 & 0.45 & PDE4A & NM 006202 & (PDE4A), mRNA \\
\hline GE6III23 & 0.45 & ZNF239 & $\overline{N M 005674}$ & zinc finger protein 239 (ZNF239), mRNA \\
\hline GE53189 & 0.46 & AUTS2 & $\overline{N M} 015570$ & autism susceptibility candidate 2 (AUTS2), mRNA \\
\hline GE8|426 & 0.46 & USP9Y & NM 004654 & ubiquitin specific protease $9, \mathrm{Y}$ chromosome (fat facets-like Drosophila) (USP9Y), mRNA \\
\hline GE63274 & 0.48 & CENTG3 & AL537305 & FETAL BRAIN cDNA clone CSODF025YC08 5-PRIME \\
\hline GE83170 & 0.48 & $\mathrm{BCL} 2 \mathrm{~L} 14$ & NM 030766 & apoptosis regulator $\mathrm{BCL}-\mathrm{G}(\mathrm{BCLG})$, transcript variant 2 , mRNA \\
\hline GE58554 & 0.49 & PROI9I4 & $\overline{N M 014106}$ & PROI9I4 protein (PROI9I4), mRNA \\
\hline GE86889 & 0.49 & SLC26A7 & NM 052832 & solute carrier family 26 , member 7 (SLC26A7), transcript variant I, mRNA \\
\hline GE8I520 & 0.49 & BCATI & NM 005504 & branched chain aminotransferase I, cytosolic (BCATI), mRNA \\
\hline
\end{tabular}

Fold change $=$ diseased $/$ normal

\section{Pathway Analysis}

The 1.5 fold list was further analyzed using Onto-Express and Pathway-Express, part of the Onto-Tools package available from the Draghici laboratory. This software allows for identification of pathways that show enrichment in the microarray data and is a novel tool that translates lists of differentially regulated genes into functional profiles characterizing the impact of the condition studied.

\section{Quantitative PCR validation}

To verify expression data obtained by the Codelink analysis, Taqman gene expression assays were obtained (Applied Biosystems) to evaluate the expression of selected genes by RTqPCR. The assays utilized were as follows: TCF2 (Applied Biosystems assay Hs01001609_m1), CXCL10 (Hs00171042_m1), FUT4 (Hs00275643_s1), SERPINB1 (Hs00229084_m1), CD9 (Hs01124026_m1), LYPLA3 (Hs00202399_m1), SERPINB9 (Hs00394497_m1), CD83 (Hs00188486_m1), CDC5L(Hs00904622_m1), TNFRSF19
(Hs00218634_m1), HLA-DRA (Hs00219578_m1). All assays are designed to detect the appropriate transcripts at an exon-exon junction to ensure the detection of mRNA and not genomic DNA.

The expression levels of these 11 genes were evaluated by two-step Taqman-based RT-qPCR. First strand cDNA was synthesized with M-MLV reverse transcriptase (Ambion, Inc., Austin, TX) and primed with oligo-dT per the manufacturer's specifications. The cDNA equivalent of $20 \mathrm{ng}$ starting RNA was then included in reactions containing $1 \times$ Taqman Master Mix (Applied Biosystems, Foster City, $\mathrm{CA}$ ), and $1 \times$ gene-specific assay reagents as recommended by the manufacturer (Applied Biosystems). All reactions were run in triplicate. Reactions that did not contain template cDNA were included as negative controls.

Reaction plates were processed on an Applied Biosystems 7900 HT Sequence Detection System. The AmpliTaq Gold polymerase was activated at $95^{\circ} \mathrm{C}$ for $10 \mathrm{~min}$ followed by 


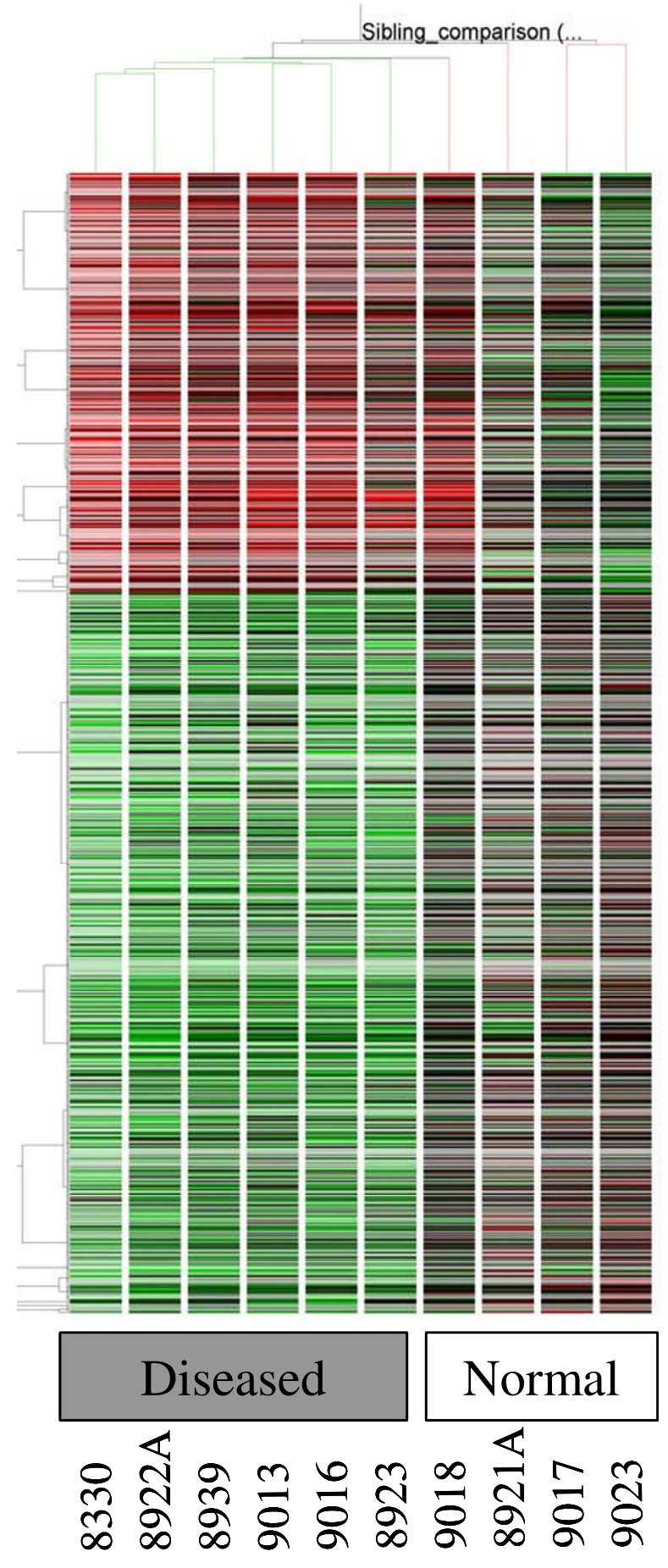

Figure I

Hierarchical clustering of all statistically significant genes that show differential expression between diseased and normal samples. Upregulated are colored red and downregulated genes are colored green. Clustering of genes is shown on the left while condition based tree is shown on the top.
40 cycles consisting of denaturation for 15 seconds at $95^{\circ} \mathrm{C}$ and annealing and extension for 60 seconds at $60^{\circ} \mathrm{C}$.

Amplification data was analyzed with the ABI Prism SDS 2.1 software (Applied Biosystems). Although run individually, samples GM8921A, 9017, 9018, and 9023 were pooled for analysis as the control sample, and samples GM8830, 8922A, 8923，8839，9013， and 9016 were pooled for analysis as the MS sample, unless otherwise noted. Relative quantification of gene expression was performed by the $\Delta \Delta \mathrm{Ct}$ method [18]. GAPDH expression was used as an endogenous control to normalize expression within each sample.

\section{Transcription network analysis}

We employed a software program that one of our authors continues to develop (G.A.) to recast the matrix of regulatory interactions found in a prior step as a directed graph overlaying color information for gene responses. Our regulatory network was constructed by integrating transcription factor binding site information (from TRANSFAC) with gene expression data using graph TFs (Bioconductor functions for transcription network analysis). The standard microarray experiments cannot measure the transcription factor activities (TFAs) directly, since TFAs are subject to post-translational modifications or ligand binding in order to exert their function.

We hypothesized that decoding some of the important TFAs involved in B cells of MS patients might provide important clues to disease pathogenesis or uncover potential molecular targets for therapy. We started with an initial list of all genes changing at the 1.5-fold level. In this dual sample study, we assumed all pairs of genes moving in the same direction to be concordant and all pairs moving in opposite directions to be discordant. Combining this with the potential for regulatory relationships inferred from a TRANSFAC binding site dataset, we were able to extrapolate the potential transcription regulatory networks driving expression changes. We found that TCF2 and CDC5L bind very similar promoter motifs and seem to control overlapping sets of up and down regulated genes in this study. The transcripts we uncovered in this dataset are most notably, CCR1 and CXCR4, molecules which are associated with MS. The multiplication of corresponding cells in the TFBS and correlation matrices yields a regulation matrix where the sign of the interaction score reflects positive or negative regulation and the magnitude of the score reflects the amount of supporting evidence, as shown in the grid below (Figure 2). We examined these networks for various thresholds of foldchange and TRANSFAC evidence scores to obtain the picture of regulation of downstream molecules by TCF2 and CDCL5 shown in Figure 3. 
TFBS Matrix

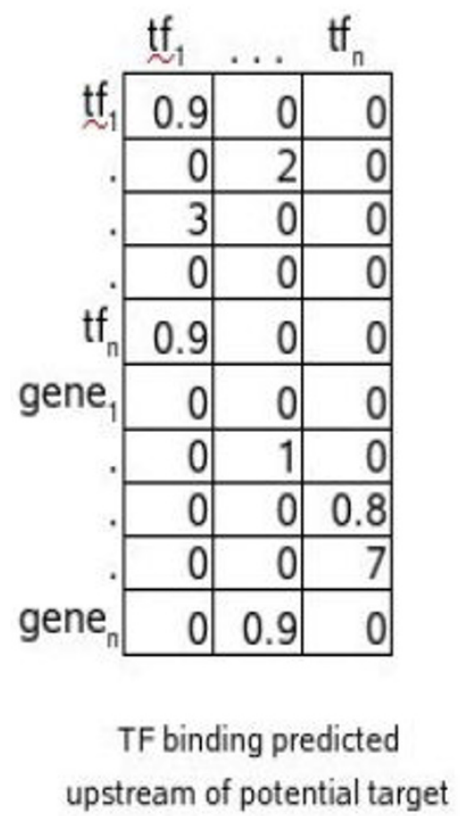

Correlation Matrix

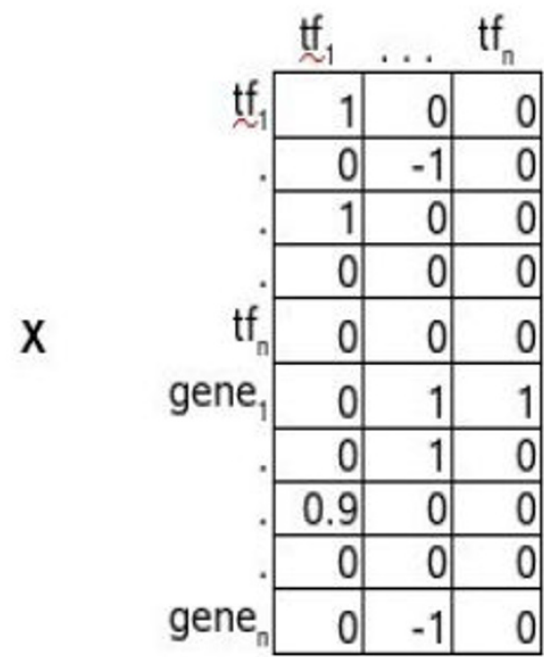

Profiles correlated or

anti-correlated with TF expression
Regulation Matrix

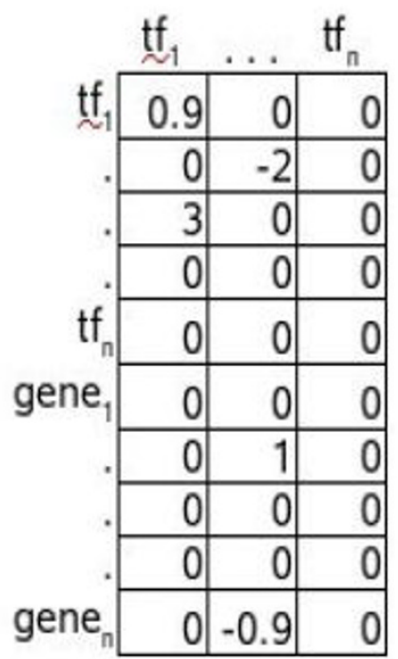

Potential up or down regulation targets of TF shown in array

Figure 2

Analysis of transcription networks from microarray data.

\section{Results}

As shown in Figure 1, the rows represent hierarchical clustering of all differentially expressed genes between the diseased (MS) and control (normal siblings) samples. The MS samples were 8923, 8922 A, 8830, 8839, 9013 and 9016, respectively. The unaffected siblings were 9017, 9018, 9023 and 8921A, respectively. Onto-Express analyses depicted in Figure 4 shows that transcription factor binding is a highly significant component in our microarray data. Results from Pathway-Express analysis are listed in Table 4, and these show that immune function and neurospecific pathways are also highly implicated in this data set.

We selected a subset of genes that were up and down regulated in the MS samples for further validation by RTqPCR. Our results generally confirmed the results obtained with the Codelink arrays. TCF2, CXCL10, and FUT4 were all up regulated in the MS samples whereas CDC5L, TNFRSF19 and HLA-DR were down regulated (Table 5).

For three other genes, we obtained disparate results for expression when the control and MS samples were pooled for analysis. CD83 was up regulated by RT-qPCR while down regulated by array analysis, SERPINB9 was down regulated by RT-qPCR while up regulated on the arrays, and CD9 was only minimally up regulated by RT-qPCR while clearly up regulated on the arrays (Table 6). For each of these genes, some samples were negative for expression by RT-qPCR (control sample 8921A for SERPINB9 and CD9, MS sample 8922A for CD83), and the influence of the negative values is not fully accounted for when pooling the samples prior to analysis by the $\Delta \Delta \mathrm{Ct}$ method. Thus, for these genes we further evaluated the RT-qPCR data by analyzing the control and MS samples individually and then averaging, rather than pooling the samples prior to the $\Delta \Delta \mathrm{Ct}$ analysis. After evaluating individual samples, we also found that some control samples were significant outliers for the CD83 and SERPINB9 genes. Control sample 8921A had a 26-fold increase in CD83 expression relative to the next highest control sample, and control sample 9018 had a 255 -fold increase in SERPINB9 expression and a 156-fold increase in CD9 expression relative to the next highest samples for those genes (data not shown). To compensate for these outliers, we eliminated the highest expression samples from both the control and MS samples from the analysis and also included the negative samples. When analyzed in this way, CD83 expression in the MS samples was down regulated by 0.58 -fold, SERPINB9 expression was up regulated by 2.47 -fold, and 


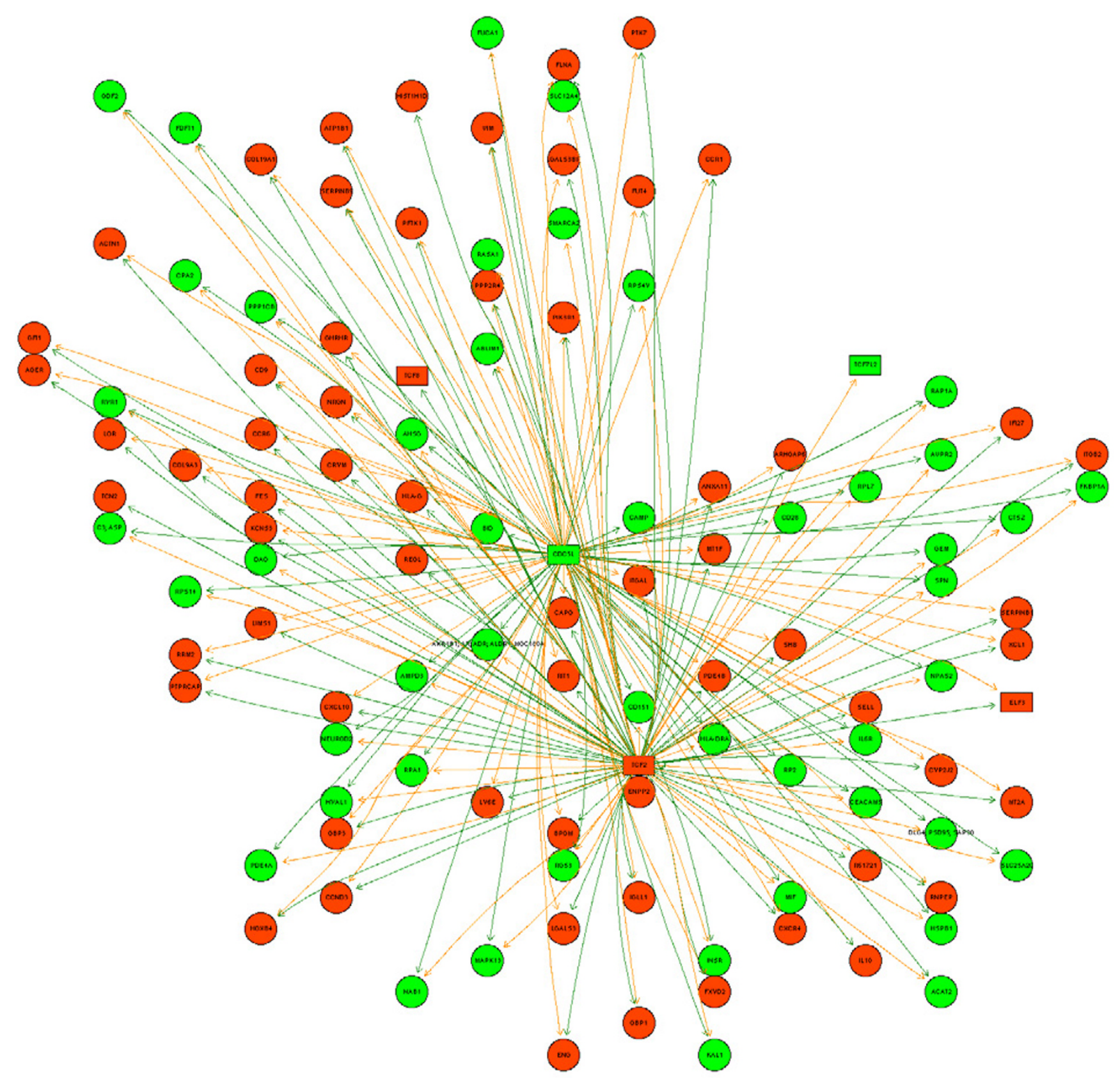

Figure 3

Transcription factor network deciphered from genes differentially expressed at a I.5 fold cutoff in microarray data. The color 'red" shows upregulation while "green" shows downregulated expression. Genes are depicted by circles while transcription factors are represented as rectangles. Green arrows indicate that the nodes at each end of the arrow are regulated in the same direction (up or down) while the red arrows connect the nodes that are anticorrelated. 


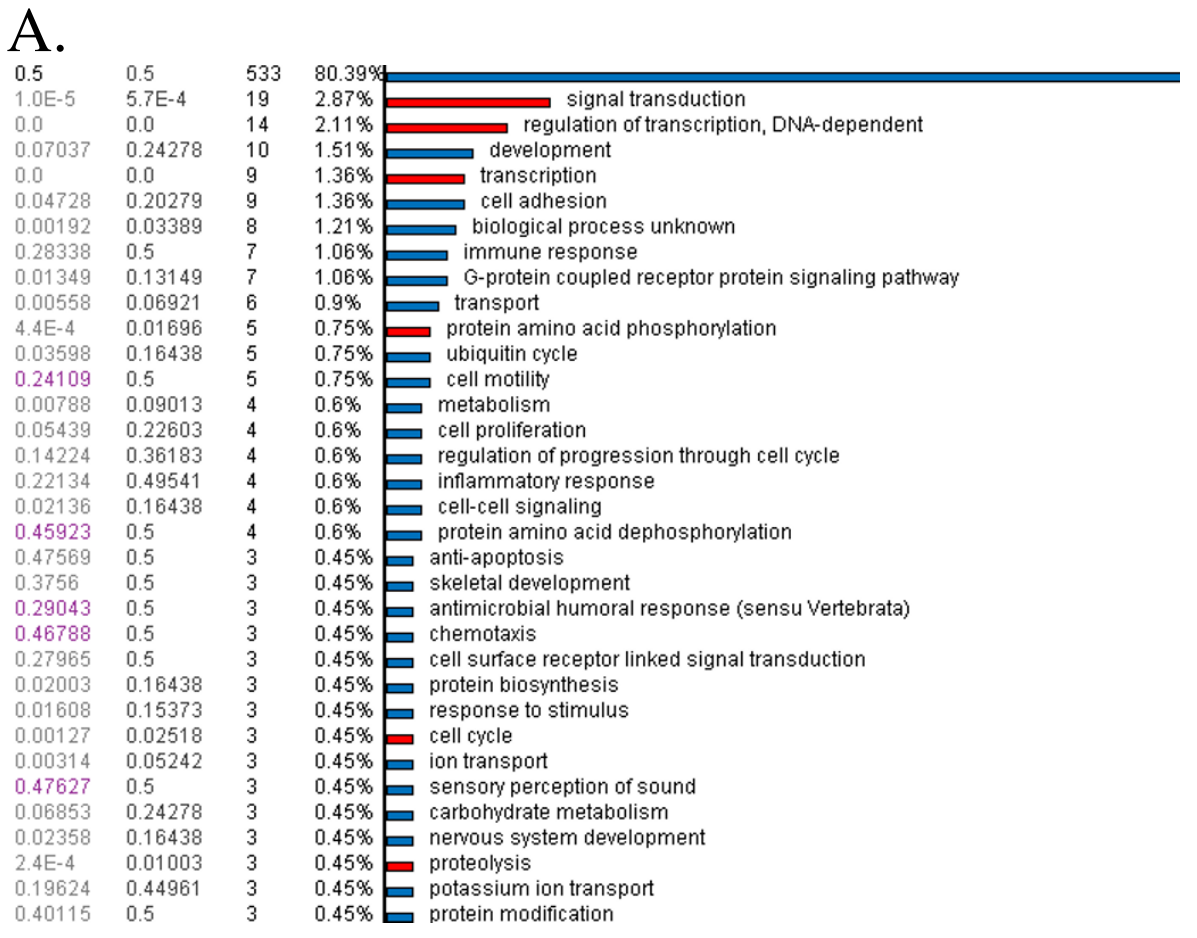

B.

\begin{tabular}{|c|c|c|c|c|}
\hline 0.5 & 0.5 & 528 & $79.64 \%$ & q \\
\hline 0.0 & 0.0 & 34 & $5.13 \%$ & protein binding \\
\hline 0.0 & 0.0 & 21 & $3.17 \%$ & zinc ion binding \\
\hline 0.0 & 0.0 & 19 & $2.87 \%$ & metal ion binding \\
\hline $5.2 \mathrm{E}-4$ & 0.00608 & 17 & $2.56 \%$ & — receptor activity \\
\hline 0.0 & 0.0 & 12 & $1.81 \%$ & nucleotide binding \\
\hline $1.0 \mathrm{E}-5$ & $2.5 \mathrm{E}-4$ & 12 & $1.81 \%$ & DNA binding \\
\hline $9.9 \mathrm{E}-4$ & 0.01007 & 9 & $1.36 \%$ & molecular function unknown \\
\hline $9.0 \mathrm{E}-5$ & 0.00138 & 9 & $1.36 \%$ & Dydrolase activity \\
\hline 0.0 & 0.0 & 9 & $1.36 \%$ & ATP binding \\
\hline $6.4 \mathrm{E}-4$ & 0.00699 & 7 & $1.06 \%$ & nucleic acid binding \\
\hline 0.0 & $5.0 \mathrm{E}-5$ & 7 & $1.06 \%$ & transcription factor activity \\
\hline 0.02743 & 0.1265 & 7 & $1.06 \%$ & RNA binding \\
\hline 0.0 & 0.0 & 7 & $1.06 \%$ & transferase activity \\
\hline 0.17996 & 0.36338 & 6 & $0.9 \%$ & rhodopsin-like receptor activity \\
\hline 0.24218 & 0.41917 & 5 & $0.75 \%$ & actin binding \\
\hline 0.02891 & 0.1265 & 4 & $0.6 \%$ & GTP binding \\
\hline 0.02191 & 0.11136 & 4 & $0.6 \%$ & transporter activity \\
\hline 0.05838 & 0.18765 & 4 & $0.6 \%$ & . structural molecule activity \\
\hline 0.17905 & 0.36338 & 4 & $0.6 \%$ & $\rightleftharpoons$ cytokine activity \\
\hline 0.4696 & 0.5 & 4 & $0.6 \%$ & sugar binding \\
\hline 0.41807 & 0.5 & 3 & $0.45 \%$ & $\sqsupseteq$ isomerase activity \\
\hline 0.00255 & 0.01962 & 3 & $0.45 \%$ & $\exists$ protein serine/threonine kinase activity \\
\hline 0.06519 & 0.20334 & 3 & $0.45 \%$ & ש iron ion binding \\
\hline 0.092 & 0.24741 & 3 & $0.45 \%$ & $\sqsupseteq$ catalytic activity \\
\hline 0.41515 & 0.5 & 3 & $0.45 \%$ & $\sqsupseteq$ potassium ion binding \\
\hline 0.29887 & 0.46607 & 3 & $0.45 \%$ & $\models$ structural constituent of cytoskeleton \\
\hline 4.3E-4 & 0.00548 & 3 & $0.45 \%$ & $\bigoplus$ oxidoreductase activity \\
\hline 0.00189 & 0.01491 & 3 & $0.45 \%$ & $D$ C-C chemokine receptor activity \\
\hline 0.27965 & 0.45219 & 3 & $0.45 \%$ & $\sqsupseteq$ GTPase activity \\
\hline $5.4 \mathrm{E}-4$ & 0.00609 & 3 & $0.45 \%$ & $\bigoplus$ sequence-specific DNA binding \\
\hline $2.2 \mathrm{E}-4$ & 0.00308 & 3 & $0.45 \%$ & $\sqsubseteq$ binding \\
\hline 0.00474 & 0.02988 & 2 & $0.3 \%$ & 曰 signal transducer activity \\
\hline 0.1096 & 0.26765 & 2 & $0.3 \%$ & 曰 structural constituent of ribosome \\
\hline 0.18692 & 0.37032 & 2 & $0.3 \%$ & e protein-tyrosine kinase activity \\
\hline
\end{tabular}

Figure 4

Results from functional profiling of data using Onto-Express. (A) The figure shows the significant (red) biological processes represented in a set of genes differentially expressed between two clinical groups. (B) The figure shows the significant (red) molecular function represented in a set of genes differentially expressed between two clinical groups. 
N Table 4: Results of pathway profiling using Pathway Express.

\begin{tabular}{|c|c|c|c|c|c|c|c|c|c|}
\hline Rank & $\begin{array}{l}\text { Database } \\
\text { Name }\end{array}$ & Pathway Name & Impact Factor & $\begin{array}{l}\text { \#Genes in } \\
\text { Pathway }\end{array}$ & $\begin{array}{l}\text { \#Input Genes in } \\
\text { Pathway }\end{array}$ & $\begin{array}{c}\text { \#Pathway Genes on } \\
\text { Chip }\end{array}$ & $\begin{array}{l}\text { \%Input Genes in } \\
\text { Pathway }\end{array}$ & $\begin{array}{c}\text { \%Pathway Genes in } \\
\text { Input }\end{array}$ & $\mathrm{p}$-value \\
\hline I & KEGG & Cell adhesion molecules (CAMs) & 6.94 & 132 & 11 & 126 & 2.099 & 8.333 & $9.69 \mathrm{E}-04$ \\
\hline 2 & KEGG & Axon guidance & 6.94 & 130 & 11 & 126 & 2.099 & 8.462 & $9.69 \mathrm{E}-04$ \\
\hline 3 & KEGG & Leukocyte transendothelial migration & 5.288 & 117 & 9 & 113 & 1.718 & 7.692 & 0.005054 \\
\hline 4 & KEGG & Type I diabetes mellitus & 5.232 & 44 & 5 & 40 & 0.954 & 11.364 & 0.005344 \\
\hline 5 & KEGG & Regulation of actin cytoskeleton & 4.461 & 206 & 12 & 198 & 2.29 & 5.825 & 0.011556 \\
\hline 6 & KEGG & Natural killer cell mediated cytotoxicity & 4.11 & 128 & 8 & 114 & 1.527 & 6.25 & 0.016401 \\
\hline 8 & KEGG & Tight junction & 3.187 & 119 & 7 & 112 & 1.336 & 5.882 & 0.041314 \\
\hline 9 & KEGG & Antigen processing and presentation & 3.112 & 86 & 5 & 68 & 0.954 & 5.814 & 0.044499 \\
\hline 10 & KEGG & Adherens junction & 2.721 & 77 & 5 & 76 & 0.954 & 6.494 & 0.065823 \\
\hline 11 & KEGG & Colorectal cancer & 2.676 & 77 & 5 & 77 & 0.954 & 6.494 & 0.068828 \\
\hline 12 & KEGG & Circadian rhythm & 2.386 & 18 & 2 & 18 & 0.382 & 11.111 & 0.091979 \\
\hline 13 & KEGG & Maturity onset diabetes of the young & 1.975 & 25 & 2 & 23 & 0.382 & 8 & 0.138816 \\
\hline 14 & KEGG & VEGF signaling pathway & 1.972 & 72 & 4 & 70 & 0.763 & 5.556 & 0.139208 \\
\hline 15 & KEGG & Fc epsilon RI signaling pathway & 1.83 & 75 & 4 & 74 & 0.763 & 5.333 & 0.160493 \\
\hline 16 & KEGG & mTOR signaling pathway & 1.811 & 49 & 3 & 49 & 0.573 & 6.122 & 0.16353 \\
\hline 18 & KEGG & Wnt signaling pathway & 1.474 & 147 & 6 & 144 & 1.145 & 4.082 & $0.22907 \mid$ \\
\hline 19 & KEGG & MAPK signaling pathway & $\mathrm{I} .44 \mathrm{I}$ & 273 & 10 & 268 & 1.908 & 3.663 & 0.236637 \\
\hline 20 & KEGG & Toll-like receptor signaling pathway & 1.416 & 91 & 4 & 88 & 0.763 & 4.396 & 0.242667 \\
\hline 21 & KEGG & B cell receptor signaling pathway & 1.318 & 63 & 3 & 63 & 0.573 & 4.762 & 0.267565 \\
\hline 22 & KEGG & $\mathrm{T}$ cell receptor signaling pathway & 1.294 & 93 & 4 & 93 & 0.763 & 4.301 & 0.274064 \\
\hline 23 & KEGG & Long-term potentiation & 1.235 & 67 & 3 & 66 & 0.573 & 4.478 & 0.290928 \\
\hline 24 & KEGG & Insulin signaling pathway & 1.143 & 135 & 5 & $|3|$ & 0.954 & 3.704 & 0.318761 \\
\hline 25 & KEGG & Type II diabetes mellitus & 1.117 & 44 & 2 & 41 & 0.382 & 4.545 & 0.327167 \\
\hline 26 & KEGG & Dentatorubropallidoluysian atrophy (DRPLA) & 1.044 & 15 & 1 & 15 & 0.191 & 6.667 & 0.352194 \\
\hline 27 & KEGG & Epithelial cell signaling in Helicobacter pylori infection & 0.997 & 46 & 2 & 45 & 0.382 & 4.348 & 0.368822 \\
\hline 28 & KEGG & Parkinson's disease & 0.992 & 16 & I & 16 & 0.191 & 6.25 & 0.370684 \\
\hline 29 & KEGG & Cytokine-cytokine receptor interaction & 0.963 & 256 & 8 & 241 & 1.527 & 3.125 & 0.381922 \\
\hline 30 & KEGG & Jak-STAT signaling pathway & 0.936 & 153 & 5 & 144 & 0.954 & 3.268 & 0.392344 \\
\hline 31 & KEGG & Apoptosis & 0.86 & 84 & 3 & 83 & 0.573 & 3.571 & 0.423249 \\
\hline 32 & KEGG & Complement and coagulation cascades & 0.6 & 69 & 2 & 64 & 0.382 & 2.899 & 0.548544 \\
\hline 33 & KEGG & Olfactory transduction & 0.523 & 31 & i & 31 & 0.191 & 3.226 & 0.592482 \\
\hline 34 & KEGG & SNARE interactions in vesicular transport & 0.468 & 36 & 1 & 34 & 0.191 & 2.778 & 0.62642 \\
\hline 35 & KEGG & Phosphatidylinositol signaling system & 0.421 & 79 & 2 & 78 & 0.382 & 2.532 & 0.656227 \\
\hline 36 & KEGG & Taste transduction & 0.317 & 53 & 1 & 45 & 0.191 & 1.887 & 0.728441 \\
\hline 39 & KEGG & Adipocytokine signaling pathway & 0.145 & 69 & 1 & 69 & 0.191 & 1.449 & 0.864684 \\
\hline 40 & KEGG & Long-term depression & 0.124 & 75 & I & 74 & 0.191 & 1.333 & 0.882976 \\
\hline 41 & KEGG & Neuroactive ligand-receptor interaction & 0.102 & 302 & 5 & 279 & 0.954 & 1.656 & 0.902917 \\
\hline 42 & KEGG & ECM-receptor interaction & 0.086 & 87 & I & 86 & 0.191 & 1.149 & 0.91743 \\
\hline 43 & KEGG & Cell cycle & 0.042 & 112 & 1 & 110 & 0.191 & 0.893 & 0.958921 \\
\hline 44 & KEGG & Calcium signaling pathway & $0.04 I$ & 176 & 2 & 173 & 0.382 & 1.136 & 0.959904 \\
\hline
\end{tabular}


Table 5: Relative Expression of Selected Genes by RT-qPCR.

\begin{tabular}{|c|c|c|c|c|}
\hline & \multicolumn{2}{|c|}{ Control } & \multicolumn{2}{|c|}{ MS } \\
\hline & RE & $+/-\mathrm{SD}$ & RE & $\mathrm{SD}$ \\
\hline TCF2 & 1.00 & 0.68 & 7.95 & 4.25 \\
\hline CXCLIO & 1.00 & 0.47 & 5.93 & 3.85 \\
\hline FUT4 & 1.00 & 0.43 & 3.93 & 2.23 \\
\hline SERPIN BI & 1.00 & 0.57 & I.7I & 1.07 \\
\hline CDC5L & 1.00 & 0.62 & 0.54 & 0.26 \\
\hline TNFRSFI9 & 1.00 & 0.40 & 0.52 & 0.28 \\
\hline HLA-DRA & 1.00 & 0.49 & 0.33 & 0.16 \\
\hline
\end{tabular}

RE; relative expression.

$+/$; calculated by determining relative expression for the value obtained by adding the $\Delta \Delta \mathrm{Ct}$ and $\Delta \mathrm{Ct}$ standard deviation (RE $+/-$ ), and then subtracting the RE +/- value from the RE.

CD9 expression was up regulated 3.5-fold relative to the Control samples (Table 6) and these results are in concordance with array data for these genes.

Although we included a Taqman assay for LYPLA3 in our validation studies, we were not able evaluate expression of this gene by RT-qPCR. None of the four Control samples were consistently positive for expression of this gene by RT-qPCR, and only one of the six MS samples was consistently positive. The probe for this gene on the Codelink array is located near the 3' end of the coding sequence whereas the Taqman assay detects sequences at the $5^{\prime}$ end of the coding sequence, at the junction between exons 1 and 2 ( 6 total exons). Thus, full length cDNA would be required to detect LYPLA3 expression with the Taqman assay we employed. Our inability to consistently detect this gene suggests that we did not generate full length LYPLA3 cDNA during the RT step - either due to mRNA instability or inefficient reverse transcription.

\section{Additional data}

A list of genes at 1.5 fold differential expression from microarray data can be found in Additional file 1 .

\section{Discussion and Conclusion}

The genes involved in our analyses encode proteins involved in apoptosis, cytokine pathways and inflammation. Although up or downregulation of gene transcription is not reflected in a 1:1 translation of protein expression, the gene product generally follows gene regu- lation dynamics [19]. A growing number of expression profiling studies provide experimental evidence indicating the presence of a transcriptionally distinct gene pattern in MS. Much of our current knowledge of MS stems from the analysis of a mouse model, experimental autoimmune encephalomyelitis (EAE) that is thought to be similar to MS. While EAE has striking clinical and histopathological similarities to MS, it has failed in predicting the efficacy of new therapeutics [20]. Our discussion is largely restricted to those genes that had $>2.5$ fold up-regulation and the two transcription factors that had the most effect on other genes. Among the total list of differentially expressed genes, the proportion of downregulated genes was higher than that of upregulated ones (262 vs. $81)$, an observation that suggests an interplay involving complex inflammatory cascades in MS.

\section{Study limitations}

The findings in our study are limited by a) sample size and b) the cellular pathways that Epstein-Barr virus (EBV) regulates remain poorly characterized and there are few data on how EBV may influence gene pathways in B cells derived from MS patients vs. controls. The ideal starting material would be to obtain native $\mathrm{B}$ cells from controls and MS patients; however, collection and processing bias are hard to eliminate in any microarray-based study.

\section{Upregulated genes}

The gene for CXCL10 (interferon- $\gamma$-inducible protein-10) encodes for an interferon (gamma)-induced, secreted pro-

Table 6: Analysis of SERPINB9, CD83, and CD9 Expression by RT-qPCR.

\begin{tabular}{cccccccc}
\hline & & SERPINB9 & & & CD83 & & CD9 \\
& Pool & Indiv & Pool & Indiv & Pool & Indiv \\
\hline $\begin{array}{c}\text { Control } \\
\text { MS }\end{array}$ & 1 & 1 & 1 & 1 & 1 & 1.23 & 3.5 \\
\hline
\end{tabular}

I. Pool; after RT-qPCR, Control and MS samples pooled prior to calculation of RE by $\Delta \Delta$ Ct method.

2. Indiv; RE of samples first determined by $\Delta \Delta \mathrm{CtC}$ method, then Control and MS sample REs averaged (see text for details). 
tein of $10 \mathrm{kDa}$, a chemokine of the CXC subfamily that is one of the ligands for the receptor CXCR3. The binding of this protein to CXCR3 causes pleiotropic effects, including stimulation of monocytes, natural killer and T-cell migration, and modulation of adhesion molecule expression (UCSC web browser). Its levels are increased in cerebrospinal fluid of MS patients with symptomatic attacks of demyelination, suggesting a role for this molecule in MS [21]. Following mouse hepatitis virus (MHV) infection in mice [22], CXCL10 (IFN inducible protein $10 \mathrm{kDa}$ ) protein was expressed during both acute and chronic stages of disease suggesting a role for this protein in disease exacerbation and chronicity. Previous studies have shown that during the acute phase of infection, $\mathrm{T}$ lymphocytes are recruited into the CNS by CXCL10. Our finding that CXCL10 upregulation (5.8-fold) in B cells from MS siblings is supportive of prior observations.

Serpin B1 is a leukocyte elastase inhibitor and regulates the activity of the neutrophil proteases elastase, cathepsin $\mathrm{G}$ and proteinase-3. In humans, serpins constitute $10 \%$ of the plasma proteins and are known as critical regulators of both thrombotic and fibrinolytic systems. Serpins participate in the regulation of the complement cascade, angiogenesis, apoptosis and innate immunity. Most of the human clade B serpins inhibit serine and/or papain-like cysteine proteinases and protect cells from exogenous and endogenous proteinase-mediated injury. As some serpins also guard cells against the deleterious effects of promiscuous proteolytic activity [23], it is possible that the cytoprotective function is a common feature of intracellular serpin clades and we hypothesize that up-regulation of serpin B1 gene may be protective in MS. While our findings need to be validated, serpin $\mathrm{B} 1$ gene may represent a novel therapeutic target to ameliorate MS, considering the importance of these molecules in regulating proteolytic cascades.

We found that FUT4 gene was upregulated by 2.5 fold. It is a member of the interleukin 1 cytokine family and the protein encoded by the gene is produced by activated macrophages as a pro-protein and processed to its active form by caspase 1 (CASP1/ICE). This cytokine is an important mediator of the inflammatory response, cell proliferation, differentiation, and apoptosis. The induction of cyclooxygenase-2 (PTGS2/COX2) by this cytokine in the central nervous system (CNS) is found to contribute to inflammatory pain hypersensitivity. FUT4 mRNA is increased in Jurkat cells undergoing apoptosis.

LYPLA3 (lysosomal phospholipase A2): Lysophospholipases are enzymes that act on biological membranes to regulate the multifunctional lysophospholipids. The protein encoded by this gene hydrolyzes lysophosphatidylcholine to glycerophosphorylcholine and a free fatty acid.
LYPLA3 is present in the plasma and thought to be associated with high-density lipoprotein. Cellular phospholipases are key participants in cellular transduction [24] and are thought to be involved in the pathogenesis of local and systemic inflammatory disorders [25]. Interestingly, cytosolic phospholipase A2 levels were found to be low, possibly reflecting proteolysis or inactivation of enzyme activity in brain MS lesions [26].

The gene for XCL1 was upregulated; it encodes for chemokines, a group of small ( $8-14 \mathrm{kD})$ molecules that regulate cell trafficking of leukocytes through interactions with a subset of 7-transmembrane, G protein-coupled receptors. Chemokines also play fundamental roles in the development, homeostasis, and function of the immune system, and they have effects on cells of the central nervous system as well as on endothelial cells involved in angiogenesis or angiostasis. The protein product of XCL1 has chemotactic activity for neutrophils may play a role in inflammation and exerts its effects on endothelial cells in an autocrine fashion. We also found PSTPIP1 (proline-serine-threonine phosphatase interacting protein 1 ) upregulated; its role in $\mathrm{MS}$ is unclear.

\section{Downregulated genes}

An important finding in our study is an 11.7-fold downregulation of eukaryotic translation initiation factor $1 \mathrm{~A}, \mathrm{Y}$ linked (EIF1AY) gene. It is thought that EIF1AY encodes for minor histocompatibility antigen (mHA) and B-cell mediated antibody response to Y-chromosome encoded histocompatibility antigens ( $\mathrm{H}-\mathrm{Y}$ antigens) is associated with maintenance of disease remission in graft-vs-host disease [27]. The B cells may provide a new target for immune intervention in chronic graft vs. host disease and whether such a correlation can be translated to chronic MS requires further study.

We found that the tumor necrosis factor receptor (TNFR) superfamily 19 gene (TNFRSF 19) was downregulated by 5.3-fold. In a recent study by Achiron et al., TNF superfamily members $14,1 \mathrm{~B}, 4$, and 6 were downregulated. The TNFR superfamily of cell surface receptors share approximately 80 amino acids within their cytoplasmic region called the death domain (DD), critical for recruiting the death machinery [28]. Individual TNF receptors are expressed in different cell types and have a range of affinities for various intracellular molecules that provide signaling and biological specificities. However, much is unknown about how individual signal transduction pathways are regulated upon activation by any particular TNF receptor, under physiological conditions [29] and while TNFR superfamily 19 genes may mediate important functions in immunity, inflammation, differentiation, cell proliferation control, and apoptosis, their specific effects in MS are unknown. 
The gene for CD83 was downregulated in MS siblings. CD83 molecules are expressed at a high level on immunecompetent, activated and mature dendritic cells. In MS, CD83-positive dendritic cells are present in occasional perivascular cuffs in lesions, suggesting that mature dendritic cells migrate to the CNS in response to chemokine signals [30].

The downregulation of insulin receptor tyrosine kinase substrate (BAIAP2L1) gene in B cells of MS siblings is significant. The insulin-like growth factor I receptor (IGF-IR), is a member of the receptor tyrosine kinase family of growth factor receptors. In rheumatoid arthritis (RA) it has been shown that IgG antibodies from the sera of patients can stimulate synovial fibroblasts through interaction with insulin-like growth factor receptor 1 (IGF-R1), provoking trafficking of $\mathrm{T}$ cells [31]. The data demonstrate, for the first time, a bridging link between B-cell activity and T-cell trafficking. In addition, they are of potential importance for the development of innovative therapeutic strategies, in which interrupting the IGF-1/ IGF-1R axis could result in sustained disease modification by affecting both the growth-factor triggered activation of fibroblasts and the accumulation of T lymphocytes. A similar link in MS has not been demonstrated but is plausible. Other genes downregulated include ADAMTS16, BID, MIF and DAPK2, involved in the apoptosis pathway.

\section{TCF2, diabetes and MS}

Our transcription and microarray analysis showed that TCF2 was upregulated. TCF2 encodes transcription factor 2, a liver-specific factor of the homeobox-containing basic helix-turn-helix family. The TCF2 protein forms heterodimers with another liver-specific member of this transcription factor family, TCF1; depending on the TCF2 isoform, activation or inhibition of transcription of target genes occurs. We found that TCF2 upregulates the CC chemokine receptor 1 (CCR1) a molecule expressed on macrophages and T cells; in MS plaques, numerous CCR1positive infiltrating macrophages and microglial cells, associated with CCL3, were found [2] and CCR1 has been associated with newly infiltrating monocytes in MS lesions [32]. CCR1-deficient mice show an attenuated EAE course [33]. Additionally, CXCR1, a pro-inflammatory molecule is upregulated by TCF2. Furthermore, TCF2 downregulated CD28, a co-stimulatory molecule involved in T-cell stimulation and IL6R, a pro-inflammatory molecule. Taken together, it is plausible that TCF2 plays a central role in the pathogenesis of MS.

Interestingly, a mutation in TCF2 has been linked to the etiology of MODY5 (Maturity-Onset of Diabetes, Type 5) and in a recent Danish nationwide cohort study, intraindividual and, to a lesser degree, intra-familial co-occurrence was evident in MS and type 1 diabetes. The underly- ing mechanisms may involve both genetic and environmental factors [34]. Individuals with type 1 diabetes are more than three times more likely to develop MS than controls; in addition, the two diseases appear to be linked, albeit to a weak extent, within families. The exact mechanism of how mutations in these transcription factors cause diabetes remains unknown. To reiterate, a link between TCF2 mutation and MODY5 has been established, while type 1 diabetics have an increased risk of MS development. Our study points to TCF2 having a prominent role in regulation of other transcription factors. In summary, the role of TCF2 in MS needs to be further explored since MODY5 and TCF2 are linked and type 1 diabetes confers increased risk of MS development.

Another transcription factor that we found in our transcription analysis, CDC5L, was downregulated. It is a well-characterized pre-mRNA splicing factor and involved in cell cycle kinetics in yeast, S. pombe; its role in MS, if any, is not characterized.

\section{Competing interests}

The author(s) declare that they have no competing interests.

\section{Authors' contributions}

JRA (Jagannadha R Avasarala) designed, conceptualized the study format and wrote the manuscript; SVC (Sridar V Chittur) did the microarray studies, analyzed the data and authored the materials and methods section; JAT (John A Tine) did quantitative RT-PCR while ADG (Ajish D George) performed the transcription factor network analysis. All authors have read and approved the final version of the manuscript.

\section{Additional material}

\section{Additional file 1}

List of genes at 1.5 fold differential expression from microarray data. The data provided represents that complete list of statistically significant genes from the microarray analysis, which show differential expression at a 1.5 fold cut-off.

Click here for file

[http://www.biomedcentral.com/content/supplementary/17558794-1-2-S1.xls]

\section{Acknowledgements}

No funding was obtained to complete this study.

\section{References}

I. Hafler DA: Multiple sclerosis. J Clin Invest 2004, I I 3:788-94.

2. Balashov KE, Rottman JB, Weiner HL, Hancock WW: CCR5(+) and CXCR3(+) $T$ cells are increased in multiple sclerosis and their ligands MIP-I alpha and IP- I 0 are expressed in demyelinating brain lesions. Proc Natl Acad Sci USA 1999, 96:6873-8. 
3. Lindsey JW: Familial recurrence rates and genetic models of multiple sclerosis. Am J Med Genet A 2005, 135:53-8.

4. Ebers GC, Bulman DE, Sadovnick AD, Paty DW, Warren S, Hader W, Murray TJ, Seland TP, Duquette P, Grey T, et al.: A populationbased study of multiple sclerosis in twins. N EnglJ Med 1986, 315:1638-42.

5. Mackay RP, Myrianthopoulos NC: Multiple sclerosis in twins and their relatives. Arch Neurol 1966, 15:449-62.

6. Robertson NP, O'Riordan Jl, Chataway J, Kingsley DP, Miller DH, Clayton D, Compston DA: Offspring recurrence rates and clinical characteristics of conjugal multiple sclerosis. Lancet 1997, 349: 1587-90.

7. Sospedra M, Muraro PA, Stefanová I, Zhao Y, Chung K, Li Y, Giulianotti M, Simon R, Mariuzza R, Pinilla C, Martin R: Redundancy in antigen-presenting function of the HLA-DR and -DQ molecules in the multiple sclerosis-associated HLA-DR2 haplotype. J Immunol 2006, I76(3): | $95 \mid-61$.

8. Luomala M, Lehtimäki T, Elovaara I, Wang X, Ukkonen M, Mattila K, Laippala $P$, Koivula T, Hurme M: A study of interleukin-I cluster genes in susceptibility to and severity of multiple sclerosis. J Neurol Sci 200I, 185: I23-7.

9. Luomala M, Elovaara I, Ukkonen M, Koivula T, Lehtimaki T: Plasminogen activator inhibitor I gene and risk of MS in women. Neurology 2000, 54:1862-4.

10. Mattila KM, Luomala M, Lehtimaki T, Laippala P, Koivula T, Elovaara I: Interaction between ESRI and HLA-DR2 may contribute to the development of MS in women. Neurology 200I, 56:I246-7.

II. Tourtellotte WW, Baumhefner RW, Syndulko K, Shapshak P, Osborne M, Rubinshtein G, Newton L, Ellison G, Myers L, Rosario I: The long march of the cerebrospinal fluid profile indicative of clinical definite multiple sclerosis; and still marching. Neuroimmunol 1988, 20:217-27.

12. Qin $Y$, Duquette $P$, Zhang $Y$, Talbot $P$, Poole R, Antel J: Clonal expansion and somatic hypermutation of $\mathrm{V}(\mathrm{H})$ genes of $B$ cells from cerebrospinal fluid in multiple sclerosis. J Clin Invest 1998, 102:1045-50.

13. Genain CP, Cannella B, Hauser SL, Raine CS: Identification of autoantibodies associated with myelin damage in multiple sclerosis. Nat Med 1999, 5: I70-5.

14. Cepok S, Zhou D, Srivastava R, Nessler S, Stei S, Büssow K, Sommer $\mathrm{N}$, Hemmer B: Identification of Epstein-Barr virus proteins as putative targets of the immune response in multiple sclerosis. J Clin Invest 2005, I I 5: I 352-60.

15. Lock C, Hermans G, Pedotti R, Brendolan A, Schadt E, Garren H, Langer-Gould A, Strober S, Cannella B, Allard J, Klonowski P, Austin A, Lad N, Kaminski N, Galli SJ, Oksenberg JR, Raine CS, Heller R, Steinman L: Gene-microarray analysis of multiple sclerosis lesions yields new targets validated in autoimmune encephalomyelitis. Nat Med 2002, 8:500-8.

16. Bittner M, Meltzer P, Chen $Y$, Jiang $Y$, Seftor E, Hendrix M, Radmacher M, Simon R, Yakhini Z, Ben-Dor A, Sampas N, Dougherty E, Wang E, Marincola F, Gooden C, Lueders J, Glatfelter A, Pollock P, Carpten J, Gillanders E, Leja D, Dietrich K, Beaudry C, Berens M, Alberts D, Sondak V: Molecular classification of cutaneous malignant melanoma by gene expression profiling. Nature 2000, 406:536-40.

17. Gene Expression Omnibus Viewer [http:www.ncbi.nlm.nih.gogeo/query/acc.cgi?token=pnsxvqskiumgevk\&acc $=$ GSE 10064$]$

18. Winer J, Jung CK, Shackel I, Williams PM: Development and validation of real-time quantitative reverse transcriptasepolymerase chain reaction for monitoring gene expression in cardiac myocytes in vitro. Anal Biochem 1999, 270:41-9.

19. Gebicke-Haerter PJ: Microarrays and expression profiling in microglia research and in inflammatory brain disorders. Neurosci Res 2005, 81:327-41.

20. Steinman L: Immunotherapy of multiple sclerosis: the end of the beginning. Curr Opin Immunol 200I, I 3:597-600.

21. Galimberti D, Scalabrini D, Fenoglio C, Comi C, De Riz M, Venturelli E, Lovati C, Mariani C, Monaco F, Bresolin N, Scarpini E: CXCLIO haplotypes and multiple sclerosis: association and correlation with clinical course. Eur J Neurol 2007, 14:162-7.

22. Liu MT, Keirstead HS, Lane TE: Neutralization of the chemokine CXCLI 0 reduces inflammatory cell invasion and demyelination and improves neurological function in a viral model of multiple sclerosis. J Immunol 200I, 167:409I-7.
23. Silverman GA, Whisstock JC, Askew DJ, Pak SC, Luke CJ, Cataltepe S, Irving JA, Bird PI: Human clade B serpins (ov-serpins) belong to a cohort of evolutionarily dispersed intracellular proteinase inhibitor clades that protect cells from promiscuous proteolysis. Cell Mol Life Sci 2004, 6 I:30I-25.

24. Dennis EA, Rhee SG, Billah MM, Hannun YA: Role of phospholipase in generating lipid second messengers in signal transduction. Faseb J 1991, 5:2068-77.

25. Pruzanski W, Vadas P: Phospholipase A2 - a mediator between proximal and distal effectors of inflammation. Immunol Today 1991, 12:143-6.

26. Huterer SJ, Tourtellotte WW, Wherrett JR: Alterations in the activity of phospholipases A2 in postmortem white matter from patients with multiple sclerosis. Neurochem Res 1995, 20:1335-43.

27. Miklos DB, Kim HT, Miller KH, Guo L, Zorn E, Lee SJ, Hochberg EP, Wu CJ, Alyea EP, Cutler C, Ho V, Soiffer RJ, Antin JH, Ritz J: Antibody responses to $\mathrm{H}-\mathrm{Y}$ minor histocompatibility antigens correlate with chronic graft-versus-host disease and disease remission. Blood 2005, 105:2973-8.

28. Shen HM, Pervaiz S: TNF receptor superfamily-induced cell death: redox-dependent execution. Faseb J 2006, 20:1589-98.

29. Dempsey PW, Doyle SE, He JO, Cheng G: The signaling adaptors and pathways activated by TNF superfamily. Cytokine Growth Factor Rev 2003, 14:193-209.

30. Plumb J, Armstrong MA, Duddy M, Mirakhur M, McQuaid S: CD83positive dendritic cells are present in occasional perivascular cuffs in multiple sclerosis lesions. Mult Scler 2003, 9:142-7.

31. Pritchard J, Tsui S, Horst N, Cruikshank WW, Smith T]: Synovial fibroblasts from patients with rheumatoid arthritis, like fibroblasts from Graves' disease, express high levels of IL-16 when treated with Igs against insulin-like growth factor-I receptor. J Immunol 2004, 173:3564-9.

32. Trebst C, Sørensen TL, Kivisäkk $P$, Cathcart MK, Hesselgesser J Horuk R, Sellebjerg F, Lassmann H, Ransohoff RM: CCRI+/CCR5+ mononuclear phagocytes accumulate in the central nervous system of patients with multiple sclerosis. Am J Pathol 200I, 159:1701-10.

33. Rottman JB, Slavin AJ, Silva R, Weiner HL, Gerard CG, Hancock WW: Leukocyte recruitment during onset of experimental allergic encephalomyelitis is CCRI dependent. Eur J Immunol 2000, 30:2372-7.

34. Nielsen NM, Westergaard T, Frisch M, Rostgaard K, Wohlfahrt J, Koch-Henriksen N, Melbye M, Hjalgrim H: Type I diabetes and multiple sclerosis: A Danish population-based cohort study. Arch Neurol 2006, 63:100 I-4.
Publish with Bio Med Central and every scientist can read your work free of charge

"BioMed Central will be the most significant development for disseminating the results of biomedical research in our lifetime. "

Sir Paul Nurse, Cancer Research UK

Your research papers will be:

- available free of charge to the entire biomedical community

- peer reviewed and published immediately upon acceptance

- cited in PubMed and archived on PubMed Central

- yours - you keep the copyright

Submit your manuscript here:

http://www.biomedcentral.com/info/publishing_adv.asp
BioMedcentral 